\title{
Smoking-Related Behaviors and Effectiveness of Smoking Cessation Therapy Among Prisoners and Prison Staff
}

\author{
Onur Turan MD and Pakize Ayse Turan MD
}

\begin{abstract}
BACKGROUND: Smoking is a serious problem in prisons. This work aimed to assess smokingrelated behaviors and the effectiveness of tobacco cessation therapy in prison. METHODS: This study includes four visits to a prison in Bolvadin-Afyon, Turkey. Pharmacologic options for tobacco cessation were offered to the participants who wanted to quit smoking. RESULTS: One hundred seventy-nine subjects (109 prisoners and 70 prison staff) with $68.7 \%$ current smokers were included. There was an increase of cigarette smoking in $41.8 \%$ (the most common reason was stress) and decrease in $18.7 \%$ (the most common reason was health problems) of the participants after incarceration. Fifty-nine participants accepted the offered tobacco cessation treatment. Only 2 participants started their planned medications, but they could not quit smoking. The most common reason for failed attempts to quit was the high prices of cessation therapies. CONCLUSION: Factors like stress and being in prison may provoke smoking. A smoking ban does not seem to be a total solution for preventing tobacco use in prisons. Tobacco cessation programs may be a better option. Cost-free cessation medications may increase quitting rates among prisoners and prison staff. Key words: smoking; prison; tobacco cessation. [Respir Care 2016;61(4):434-438. () 2016 Daedalus Enterprises]
\end{abstract}

\section{Introduction}

The prevalence of smoking in prisons has been found to be higher than in the civilian population. ${ }^{1}$ Exposure to secondhand smoke is also known to be high among prisoners and prison staff. ${ }^{2}$ Incarcerated people have had higher rates of chronic diseases exacerbated by smoking, ${ }^{3}$ which shows that smoking is a devastating problem for prisons.

Tobacco control strategies have generally succeeded in reducing smoking in public populations. However, this does not hold true for prison populations. Smoking has been a part of prison culture for a very long time. ${ }^{4}$ Factors like stress, depression, and exposure to secondhand smoke have been high among prisoners, ${ }^{5}$ which may lead to higher smoking rates in prisons after incarceration.

\footnotetext{
The authors are affiliated with the Chest Diseases Department, Gelibolu State Hospital, Canakkale, Turkey and the Chest Diseases Department, Canakkale State Hospital, Canakkale, Turkey.
}

The authors have disclosed no conflicts of interest.

Correspondence: Onur Turan MD, Chest Diseases Department, Gelibolu State Hospital, Canakkale, Turkey 17000. E-mail: onurtura@yahoo.com.

DOI: $10.4187 /$ respcare. 04122
Smoking is one of the most prominent public health issues among prisoners. This harmful behavior negatively impacts the health of prisoners. ${ }^{6}$ Forcing tobacco bans in prisons may improve the health of prisoners, decrease secondhand smoke concentrations in prisons, and reduce the costs for treatment for smoking-related illnesses. ${ }^{4}$

Insufficient attention and help have been given to prisoners for quitting smoking in prison. ${ }^{7}$ Currently, there are either indoor smoking areas or total bans on tobacco use in the majority of correctional systems. ${ }^{8}$ Despite bans on indoor smoking, the majority of smokers in one study said that they broke the rules and smoked inside the prisons. ${ }^{6}$ On the other hand, total tobacco bans may also bring some problems, such as symptoms of withdrawal in those who stop smoking after incarceration. ${ }^{9}$ Unfortunately, it seems that smoking bans do not have a great impact on smokers, since they continue smoking during imprisonment. ${ }^{4}$ Lincoln et $\mathrm{al}^{10}$ noted that most of the smokers who stopped smoking because of bans had returned to tobacco use after release from jail.

There is a lack of data in the literature about attitudes of prisoners and prison staff toward smoking and tobacco cessation in prisons. This study aims to assess the smoking-related behaviors and the effectiveness of tobacco cessation therapy in prison. 


\section{Smoking Behaviors and Cessation Effectiveness in Prison}

\section{Methods}

The study was performed in Bolvadin Closed and Open Prison, Afyon, Turkey. In this prison, no smoking was allowed indoors. Prisoners were allowed to go outdoors during specific times of the day to smoke.

The Ministry of Justice and our local ethics committee granted ethical approval for our study. All participants, including prisoners and prison staff, provided written informed consent. Inclusion criteria were participants $>18 \mathrm{y}$ old and the ability to verbally communicate. Prisoners and staff who declined to join the study or were in prison for $<3$ months were excluded.

This prospective study consisted of four visits to the prison. During the first visit, personal meetings with the prisoners and prison staff were held. Participant demographics, imprisonment status, and a smoking history (age at initiation of smoking, pack-years, the number of cigarettes smoked per day, use of any other tobacco products, changes in smoking habits and secondhand smoke in prison, desire to quit smoking, previous attempts to quit, previous smoking cessation therapies, questions about the effects of tobacco use on health, and opinions about a law that prohibits use of tobacco products in closed public areas in Turkey) were recorded. Participants also completed the Fagerström test for nicotine dependence. ${ }^{11}$

Current smokers, ex-smokers, and never-smokers were defined according to the World Health Organization criteria. ${ }^{12} \mathrm{~A}$ smoker is a person who smokes any tobacco product either daily or occasionally at the time of the survey. An ex-smoker is a person who was formerly a daily smoker but has not smoked in the last 6 months. A never-smoker is a person who either has never smoked at all or has never been a daily smoker and has smoked $<100$ cigarettes (or the equivalent amount of tobacco) in his/her lifetime.

Pharmacologic options for smoking cessation treatment were offered to the participants with a moderate or high nicotine dependence level who wanted to quit smoking. Benefits of tobacco cessation and the cessation process along with the possible withdrawal symptoms were explained to the subjects. Medications currently approved by the United States Food and Drug Administration for smoking cessation, including nicotine replacement therapy (patch, gum, lozenge, inhaler, and nasal spray), bupropion, or varenicline, were prescribed for the participants who opted to use medical therapy for quitting smoking. ${ }^{13}$ All types of smoking cessation were prescribed for each participant.

The following visit was performed 1 month after the first visit and included only the participants who were offered pharmacotherapy for smoking cessation. The subjects' data about cessation were recorded (whether they had used the chosen therapy, whether they had managed to

\section{QUICK LOOK}

\section{Current knowledge}

Smoking is still a serious problem in prisons. The percentage of secondhand smoke is high among prisoners and prison staff.

\section{What this paper contributes to our knowledge}

The mean number of cigarettes smoked in the prison per day increased after incarceration. Factors like stress and being in prison provoked smoking among the prisoners. The prisoners preferred not to purchase tobacco cessation drugs because of their economic status during incarceration.

quit smoking, their present smoking status, adverse effects of the medications, withdrawal symptoms, and their opinions about the tobacco cessation interview). Monthly visits (during the first, second, and sixth months) were performed with the participants who had started to use medications for smoking cessation.

All of the visits and meetings were performed by the same chest physician. A general conference about smoking was initially held with all prisoners and staff. There were face-to-face sessions about tobacco cessation and treatment.

Statistical analyses were performed with SPSS 13.0 (SPSS, Chicago, Illinois). The mean was used to present the results according to the data distribution. The nonparametric Mann-Whitney U test was used for analysis among groups without normal distribution. Pearson correlation was used to investigate the relationship between the variables. The chi-square test or Fisher exact test was used to compare proportions. In all tests, $P$ values of $<.05$ were considered statistically significant.

\section{Results}

One hundred seventy-nine subjects (109 prisoners and 70 prison staff) were included in the study. There were 166 men $(92.7 \%)$ and 13 women $(7.3 \%)$ with a mean age of 35.6 y. There were 123 current smokers $(68.7 \%), 26$ exsmokers $(14.5 \%)$, and 30 never-smokers $(16.8 \%)$.

The mean number of cigarettes smoked in prison per day increased by 2.1 (from 20.2 to 22.3) after incarceration. Fifty-six participants $(44.1 \%)$ described an increase, and $49(38.6 \%)$ revealed that there was no change in their number of cigarettes per day. Only 22 subjects said that they had reduced the amount of smoking (17.3\%) in the prison. The prisoners with a high nicotine dependence level were found to smoke more cigarettes in the prison $(P<.001)$. 
Table 1. Smoking Behaviors of Prisoners (Rate of Smoking: 82.6\%) and Prison Staff (Rate of Smoking: 47.1\%)

\begin{tabular}{|c|c|c|c|}
\hline Smoking Behaviors & Median & Range & $P^{*}$ \\
\hline Pack-years & & & $<.001$ \\
\hline Prisoners & 20 & $0-100$ & \\
\hline Prison staff & 11 & $0-60$ & \\
\hline Cigarettes/d & & & .11 \\
\hline Prisoners & 20 & $0-60$ & \\
\hline Prison staff & 20 & $0-50$ & \\
\hline Fagerström test score & & & .60 \\
\hline Prisoners & 4 & $0-9$ & \\
\hline Prison staff & 4 & $0-8$ & \\
\hline Cigarettes/d before prison $\ddagger$ & & & .77 \\
\hline Prisoners & 20 & $0-100$ & \\
\hline Prison staff & 20 & $0-40$ & \\
\hline Cigarettes/d after prison $\S$ & & & .16 \\
\hline Prisoners & 20 & $0-100$ & \\
\hline Prison staff & 20 & $0-40$ & \\
\hline \multicolumn{4}{|c|}{$\begin{array}{l}\text { * Mann-Whitney U test used as a non-parametric test. } \\
\text { ¥ Before incarceration or starting work at the prison. } \\
\text { \$ After incarceration or starting work at the prison. }\end{array}$} \\
\hline
\end{tabular}

Health problems (40.9\%), economic factors (36.4\%), restriction of smoking areas (13.6\%), and doctors' advice $(9.1 \%)$ were the most common reasons for reducing smoking in the prison. The most popular reasons for increasing the amount of cigarettes in the prison were said to be stress $(85.7 \%)$, being in prison $(10.7 \%)$, and a love of smoking $(7.1 \%)$.

The most common respiratory symptoms were described as: cough $(20 \%)$, sputum $(16.7 \%)$, and dyspnea $(8.5 \%)$. The presence of pulmonary symptoms was found to be statistically high in smokers compared with neversmokers and ex-smokers in the prison $(P<.001)$.

The rate of current smokers for prisoners $(82.6 \%)$ was significantly higher than for prison staff $(47.1 \%)(P<.001)$. The mean of cigarettes/day was higher in prisoners $(P<.001)$ (Table 1).

$82.9 \%$ of participants and all current smokers indicated that they had been smoking at home. Ninety-six participants $(78 \%)$ were smoking near non-smokers in the prison and caused them to be exposed to secondhand smoke. $89.4 \%$ of participants said that they were exposed to secondhand smoke in the prison. There was a significant relationship between smoking at home and causing secondhand smoke in the prison $(P=.04)$.

Of the active smokers, $78 \%$ were thinking about quitting. The scientifically proven methods to quit smoking were preferred with a rate of $78.9 \%$. Of the active smokers, $75.9 \%$ had ever tried quitting smoking, but only $9.7 \%$ of participants had used scientific methods for tobacco cessation.
Support for closed area restrictions on smoking was $88.3 \%$, and support for the law banning smoking in closed public areas was $93.9 \%$. Support for the law by neversmokers and ex-smokers was statistically significantly higher than support by current smokers in the prison $(P=.01)$. Of the 179 participants, $165(92.2 \%)$ said that they were aware of the risks of smoking and secondhand smoke.

Tobacco cessation treatment was offered to 63 participants (49 prisoners and 14 prison staff) with a moderate or high nicotine dependence level. Of these participants, 59 accepted the use of medical therapy for quitting smoking. It was decided to treat 38 smokers with varenicline, 12 with nicotine replacement therapy, and 9 with bupropion after the first visit.

The second visit was made to 40 participants after 1 month of the planned tobacco cessation therapy. Nineteen of these prisoners were released or transferred to other prisons; therefore, their final smoking condition could not be determined. Only 2 participants $(3.4 \%)$, one prisoner and one prison staff, had started to use their planned medications for tobacco cessation (one with varenicline and the other with nicotine replacement therapy). Both of them said that they had experienced no adverse effects of the medications. However, they did not use their medical therapy regularly. The remaining 38 subjects neither used medications for cessation nor quit smoking. The most popular reasons for the failed attempts were indicated as: the high prices of tobacco cessation therapies (40\%), an unsuitable prison environment (35\%), and a strong desire to smoke (25\%). Thirty-one of them (77.5\%) declared no change in the number of cigarettes per day, and only the remaining 9 participants $(22.5 \%)$ said that they had reduced their amount of smoking per day.

There was widespread agreement among participants that the meetings about tobacco cessation were useful $(83.8 \%)$. Of the prisoners, $74.1 \%$ declared that they wanted to try to quit after leaving prison.

\section{Discussion}

Reasons for smoking are still the same and in effect in prisons. Therefore, the rate of smoking may also remain high or increase among prisoners. In our study, $69 \%$ of the participants reported using tobacco in prison, and $44 \%$ indicated a rise in smoking after incarceration. There are many factors that may affect the prevalence of smoking in prisons, such as psychosocial factors, lifestyle in jails, educational status, and levels of nicotine dependence. ${ }^{7}$ The most important risk factor that can provoke smoking in prisons was demonstrated to be stress, especially resulting from imprisonment. ${ }^{7}$ Cropsey et al ${ }^{14}$ also found that more nicotine-dependent prisoners continued smoking more after incarceration. Our study, which demonstrated that the 
high rate of smoking was directly proportional to levels of nicotine dependence and stress, confirms these results.

Despite the high rates of smoking in prison, most participants were aware of the risks of smoking, and they supported the law regarding closed area restrictions on smoking. Also, it was remarkable that current smokers in the prison reported their interests in quitting. These results seem to be similar to those of previous studies. ${ }^{6,15}$ It has been reported that more than a quarter of the smokers make an attempt to quit during incarceration. ${ }^{6}$ This may be an indication that tobacco cessation programs may be more successful when they focus on current smokers in prisons with an interest in quitting. ${ }^{16}$ It is thought that attempts to quit may be more successful with professional support for smoking cessation for incarcerated people.

Although many prisons have implemented smoking bans, only a few prisons have performed tobacco cessation programs. ${ }^{3}$ Sieminska et $\mathrm{al}^{7}$ revealed that two thirds of smokers indicated that they could participate in a smoking cessation program offered by the prison. Almost $80 \%$ of incarcerated smokers declared that they would prefer scientifically proven methods for tobacco cessation in our study. This shows that a smoking cessation program may be a preferred option for current smokers in prison.

It has been demonstrated that only a few participants managed to quit smoking in prisons in other studies, ${ }^{6}$ which is concordant with our results. However, only 2 participants used their planned pharmacotherapy after visits about cessation. The most important reason for this low treatment adherence for tobacco cessation was said by our study population to be the high prices of medical therapy. The Turkish government does not pay for nicotine replacement products, bupropion, or varenicline, which means that they were self-paid drugs in our study. Kauffman et $\mathrm{al}^{6}$ specified that it is not surprising for prisoners not to purchase tobacco cessation drugs with their low economic status during incarceration. Free smoking cessation medications to all incarcerated smokers may increase the rates of quitting smoking and have a significant impact on their health.

Our study revealed that all participants who were smoking in the prison had also been smoking prior to incarceration or starting work at the prison. Another result of our study was the significant relationship between smoking at home and causing secondhand smoke in the prison. This can be explained by prisoners perceiving prisons as their homes. ${ }^{4}$ Secondhand smoke may lead to some airway problems for both smokers and non-smokers, which means that it can be an important threat for prisoners. ${ }^{17}$ Non-smoking prisoners may not be aware that prisons have common living areas, which may lead to secondhand smoke exposure.

The rate of current smokers was higher in prisoners compared with prison staff. However, it was reported that nearly half of prison staff were smoking in our study. Although most of the United States facilities disallowed smoking for prisoners, prison staff members are generally free to smoke in prisons. ${ }^{18}$ Some precautions may be taken by smokers among the prison staff to improve their health status and to decrease the level of secondhand smoke.

There are limitations to this study. Only 2 subjects used the planned therapies for smoking cessation, so it is hard to evaluate the success of smoking cessation medications. The environmental impact and settings of the prison may have influenced the answers of prisoners and prison staff about smoking habits in prison. Another limitation is that the Turkish Ministry of Justice did not allow questions about adherence to the rules of the indoor ban in prison. They declared that the questions such as Are you smoking inside correctional facilities? and Have you ever been warned or disciplined about smoking in indoor places of the prison? could be inconvenient for the safety of the prison. It was not possible to evaluate the effectiveness of the indoor smoking ban completely.

\section{Conclusions}

Smoking is a serious problem in prisons. Factors like stress and being in prison may provoke smoking among prisoners. A smoking ban does not seem to be a perfect solution for preventing tobacco use in prisons. A tobacco cessation program with professional support for smokers who want to quit may be a better option than preventing smoking with a ban in prisons. Since prisoners prefer not to purchase tobacco cessation drugs because of their economic status during incarceration, free smoking cessation medication for all incarcerated smokers may increase the rates of quitting smoking.

\section{REFERENCES}

1. Clarke JG, Martin RA, Stein L, Lopes CE, Mello J, Friedmann P, Bock B. Working Inside for Smoking Elimination (Project W.I.S.E.) study design and rationale to prevent return to smoking after release from a smoke free prison. BMC Public Health 2011;11:767.

2. Hill S, Blakely T, Kawachi I, Woodward A. Mortality among "never smokers" living with smokers: two cohort studies, 1981-4 and 1996-9. BMJ 2004;328(7446):988-989.

3. Thibodeau L, Seal DW, Jorenby DE, Corcoran K, Sosman JM. Perceptions and influences of a state prison smoking ban. J Correct Health Care 2012;18(4):293-301.

4. Butler T, Richmond R, Belcher J, Wilhelm K, Wodak A. Should smoking be banned in prisons? Tob Control 2007;16(5):291-293.

5. Hong NS, Kam S, Kim KY. Factors related to increasing trends in cigarette smoking of adolescent males in rural areas of Korea. J Prev Med Public Health 2013;46(3):139-146.

6. Kauffman RM, Ferketich AK, Murray DM, Bellair PE, Wewers ME. Tobacco use by male prisoners under an indoor smoking ban. Nicotine Tob Res 2011;13(6):449-456.

7. Sieminska A, Jassem E, Konopa K. Prisoners' attitudes towards cigarette smoking and smoking cessation: a questionnaire study in Poland. BMC Public Health 2006;6:181. 


\section{Smoking Behaviors and Cessation Effectiveness in Prison}

8. Kauffman RM, Ferketich AK, Wewers ME. Tobacco policy in American prisons, 2007. Tob Control 2008;17(5):357-360.

9. Gautam J, Glover M, Scott A, Welch D. Smokefree prisons in New Zealand: maximising the health gain. N Z Med J 2011;124(1338): 100-106.

10. Lincoln T, Tuthill RW, Roberts CA, Kennedy S, Hammett TM, Langmore-Avila E, Conklin TJ. Resumption of smoking after release from a tobacco-free correctional facility. J Correct Health Care. 2009; 15(3): 190-196.

11. Heatherton TF, Kozlowski LT, Frecker RC, Fagerström KO. The Fagerström test for nicotine dependence: a revision of the Fagerström tolerance questionnaire. Br J Addict 1991;86(9):1119-1127.

12. World Health Organization. WHO report on the global tobacco epidemic: warning about the dangers of tobacco, 2011: warning about the dangers of tobacco. Geneva: World Health Organization 2011. http://www.who.int/tobacco/global_report/2011/en/. Accessed November 2, 2015.
13. Jiloha RC. Pharmacotherapy of smoking cessation. Indian J Psychiatry 2014;56(1):87-95.

14. Cropsey KL, Kristeller JL. The effects of a prison smoking ban on smoking behavior and withdrawal symptoms. Addict Behav 2005; 30(3):589-594.

15. Cropsey K, Eldridge GD, Ladner T. Smoking among female prisoners: an ignored public health epidemic. Addict Behav 2004;29(2): 425-431.

16. Makris E, Gourgoulianis KI, Hatzoglou C. Prisoners and cigarettes or "imprisoned in cigarettes"? What helps prisoners quit smoking? BMC Public Health 2012;12:508.

17. Upton MN, Smith GD, McConnachie A, Hart CL, Watt GC. Maternal and personal cigarette smoking synergize to increase airflow limitation in adults. Am J Respir Crit Care Med 2004;169(4):479487.

18. Wyatt C. Improving the health of captive population. Health Management 2004;8(2):14-16. 